\title{
Microwave-irradiated green synthesis of gold nanoparticles for catalytic and anti-bacterial activity
}

\author{
Srinivasarao Sunkari ${ }^{1}$, Bhagavanth Reddy Gangapuram ${ }^{1,2}$, Ramakrishna Dadigala', Rajkumar Bandi', \\ Madhusudhan Alle ${ }^{1,3}$ and Veerabhadram Guttena ${ }^{1^{*}}$
}

\begin{abstract}
Background: Herein, we report a green, microwave irradiated synthesis of gold nanoparticles by using a simple, low cost and ecofriendly technique. The green technique has been developed for the synthesis of gold nanoparticles (AuNPs) from $\mathrm{HAuCl}_{4}$ using papaya leaf extract. The papaya leaf extract served both as a reductant and a stabilizer.

Method: The synthesized AuNPs had been characterized by UV-Visible spectrophotometer, Fourier transform infrared spectroscopy (FTIR), X-ray diffraction (XRD), Zeta potential and Transmission electron microscopy (TEM) techniques.

Results: The results indicated that the synthesized nanoparticles were crystalline, stable, well dispersed and spherical in shape and had an average diameter of $15 \pm 2 \mathrm{~nm}$. The AuNPs showed excellent catalytic activity for the reduction of p-nitrophenol (4-NP) to p-aminophenol (4-AP) in the presence of $\mathrm{NaBH}_{4}$. The effects of concentration of $\mathrm{NaBH}_{4}$, catalyst dose and temperature on the formation of nanoparticles were studied. The activation energy was found to be $28.15 \pm 1.14 \mathrm{~kJ} / \mathrm{mol}$.

Conclusions: The papaya leaf extract capped AuNPs are highly stable, and have showed effective catalytic activity in the reduction of 4-NP to 4-AP and antimicrobial activity on both gram-positive and gram-negative bacteria.
\end{abstract}

Keywords: Gold nanoparticles, Papaya leaf extract, Antimicrobial activity, Catalysis

\section{Background}

In recent years, nano-sized materials have played a significant role in science and technology, due to their unique size, shape, and potential applications. Metal nanoparticles are unique building blocks with sophisticated electromagnetic, chemical and optical properties that differ dramatically from those of bulk metals (Murray 2008; Sardar et al. 2009). Among several metal nanoparticles, gold nanoparticles have excellent applications in diagnostics, imaging, sensing, catalytic, electrical, magnetic, anti-bacterial activity, and drug delivery (Cuenca et al. 2006; Ulvestad et al. 2015; Ojo et al. 2016; Deng et al. 2014; Reddy et al. 2015a; Dahl et al 2007; Prakash et al. 2013; Madhusudhan et al. 2014; Rodri'guez-Sa'nchez et al 2000; Lateef et al. 2016).

\footnotetext{
* Correspondence: gvbhadram@gmail.com

'Department of Chemistry, University College of Science, Osmania University, Hyderabad, Telangana state 500007, India

Full list of author information is available at the end of the article
}

Nanoparticles have been synthesized physically, chemically, electrochemically, and photochemically (Siavash 2011; Farkas et al. 2010). Among various methods, chemical reduction of $\mathrm{Au} 3+$ ions is considered to be the best way to synthesize AuNPs with controlled size and morphology. The conventional chemical reduction methods involve the usage of strong reducing agents like $\mathrm{NaBH} 4$, hydrazine etc. However, the usage of such chemical reagents, which are harsh, toxic, expensive, and ecologically injurious, are to be avoided in the synthesis of AuNPs. Hence, the above mentioned methods are non-ecofriendly in nature and have characteristic drawbacks. The replacement of harsh synthesis methods with environmentally friendly, clean, and non-toxic green synthetic methods are very much needed for the synthesis of AuNPs (Punuri et al. 2012; Sadeghi 2015). Several biological systems such as fruit extract, fungi, plants and bacteria can actively reduce metal ions to form metal nanoparticles in environmentally friendly conditions. Recently, green syntheses of gold 
nanoparticles by using Zizyphus mauritiana extract, palm oil mill effluent, enzymes, garlic extract, gum kondagogu and acacia nilotica are reported (Gan et al. 2012; WhiteII et al. 2012; Adelere and Lateef 2016; Reddy et al. 2015b; Majumdar et al. 2013).

In this communication, we investigated the use of papaya leaf extract as reducing and stabilizing agent for the synthesis of AuNPs. Papaya belongs to the family Caricaceae and commonly known as Paw Paw, Kates, and Papaw, and is a medicinal plant. The leaves of papaya have been shown to contain many active components such as papain, chymopapain, cystatin, $\alpha$-tocopherol, ascorbic acid, flavonoids, cyanogenic glucosides, and glucosinolates (Seigler et al. 2002). The papaya bark, leaf, and fruits are being used as medicines to treat several diseases such as amenorrhoea, general debility, constipation, corns, cutaneous tubercles, warts, sinuses, eczema, glandular tumours, blood pressure, diabetes, malaria, expel worms, gonorrhoea, and syphilis (Aravind et al. 2013; Sinhalagoda et al. 2013; Rashed et al. 2013). The previous work suggests that papaya fruit extract acted as an immunostimulant and possess antioxidant properties against acrylamide toxicity in rats. The extracts of papaya fruit and leaf are rich in phenols, proteolytic enzymes, vitamins, which can act as excellent antioxidants (Kadry 2012; Reddy et al. 2015c; Layek et al 2012).

Gold in a bulk form has been observed to be a poor catalyst. But gold in the form of nanoparticles shows excellent catalytic activity towards the deoxygenation of epoxides into alkenes and reduction of ferrocyanate (III) and nitroarenes (Reddy et al. 2015a; Ju and Parales 2010). The 4-NP, along with other nitro phenols and derivatives, is a common by-product in the production of pesticides, synthetic dyes, drug industries and herbicides. Nitrophenols are refractory pollutants and are poisons due to their inhibitory nature and toxicity. In addition, nitrophenols have high stability and solubility in water. These nitrophenols tend to get accumulated in deep soil and stay indefinitely. 4-NP is considered as a diesel exhaust particle and it has an adverse impact on both male and female reproductive functions (Balakumar and Prakash 2016a). 4-NP is a well-known dangerous pollutant it causes damage to the central nervous system, erythema, kidney, liver, scaling, and cracking of the skin and causes headaches, eye irritation, infertility, and drowsiness (Balakumar and Prakash 2016b). Ecological contaminants such as 4-NP can adversely affect child development in various ways resulting in impaired fertility, fetal death, altered fetal growth, and birth defects some of which may not become apparent for years (Balakumar and Prakash 2015). Due to this reason, the reduction of 4-NP into 4-AP is an important one (Gangula et al. 2011). A variety of catalysts were reported in the past and recently, silver nanoparticles, gold nanoparticles and platinum nanoparticles have been used as catalysts for the reduction of 4-NP (Barad and Chakraborty 2014; Martı'nez et al. 2012).

In the present work, we report a rapid, green method for the synthesis of AuNPs using papaya leaf extract as reducing and stabilizing agent. Novelty of the present work lies in the usage of Papaya leaf extract, which is a cheap, readily available, and renewable resource and the use of microwave irradiation which results in the formation of AuNPs in less than 2 min of time. As synthesized AuNPs have been characterized by UV-Vis, FTIR, XRD, TEM. AuNPs were explored for their prospective catalytic and antibacterial applications.

\section{Materials}

Chloroauric acid was purchased from Sigma-Aldrich, sodium borohydride, nitric acid, hydrochloric acid, and p-nitrophenol; all reagents were purchased from S-D Fine chemicals and used without further purification.

\section{Methods \\ Preparation of the plant extract}

The fresh papaya leaves were collected from the papaya plant and were cut into fine pieces and dried under shade. After drying, it was powdered and used for further studies. One gram of leaf powder was taken in $100 \mathrm{ml}$ Erlenmeyer flask containing double distilled water and heated at $55{ }^{\circ} \mathrm{C}$ for $30 \mathrm{~min}$ to facilitate the formation of aqueous extract. The obtained extract was filtered with Whatman No.1 filter paper and the filtrate was stored for further investigation.

\section{Synthesis of gold nanoparticles}

All glassware, used in the synthesis of AuNPs were washed with aquaregia $\left(3: 1 \mathrm{HCl}-\mathrm{HNO}_{3}\right)$ and then thoroughly rinsed with double distilled water. All the solutions were prepared in double distilled water. Papaya leaf extract $(4 \mathrm{ml})$ was mixed with $1.5 \mathrm{ml}$ of chloroauric acid solution in a boiling tube and the mixture was subjected to microwave irradiation for $60-90 \mathrm{~s}$ at $750 \mathrm{~W}$ power. The resulting solution was of blushing red color, indicating the formation of gold nano particles (Chao et al. 2013). After formation, the AuNPs were centrifuged and dispersed in Milli- $Q$ water. The centrifugation and dispersion process was repeated twice to remove any unreacted $\mathrm{HAuCl}_{4}$ and leaf extract from the final product. These purified AuNPs were then used for further characterization.

\section{Characterization}

The spectra of AuNPs was recorded by UV-Vis (Shimadzu, Japan). Fourier transform infrared spectra of native papaya leaf extract and papaya leaf extract capped AuNPs was recorded with an instrument IR Affinity-1 
(Shimadzu) in the scanning range of $500-4000 \mathrm{~cm}^{-1}$. The morphology and size distribution of the papaya leaf extract capped AuNPs was investigated by transmission electron microscopy, by casting the nanoparticle dispersion on carbon-coated copper grids and allowed to dry at room temperature. Measurements were made on TECHNAI G2 F30 S-TWIN instrument. The crystallinity of the AuNPs was studied by X-ray diffraction equipment (Rigaku, MiniFlex) using $\mathrm{Cu} k \alpha$ radiation.

\section{Catalytic reduction of $\mathrm{p}$-nitrophenol}

As a model reaction, we selected the reduction of 4-NP to $4-\mathrm{AP}$ by $\mathrm{NaBH}_{4}$. The reduction was followed with the aqueous solution in a standard quartz cell having a $1-\mathrm{cm}$ path length. The reaction process was as follows: 1.5 of $0.15 \mathrm{mM} 4-\mathrm{NP}$ was mixed with $1.0 \mathrm{~mL}$ of $0.02 \mathrm{M} \mathrm{NaBH}_{4}$ in the cell for UV-Vis measurements. Immediately, the colour change was observed from light yellow to deep yellow. $0.5 \mathrm{~mL}$ of AuNPs solution was added to the above mixture. The UV-vis spectra were recorded with a time interval of $1 \mathrm{~min}$ in a scanning range of 200$600 \mathrm{~nm}$ at ambient temperature $\left(25 \pm 2{ }^{\circ} \mathrm{C}\right)$. The effects of varying the temperature, amount of catalyst and concentration of $\mathrm{NaBH}_{4}$ were carried out for the conversion of 4-NP to 4-AP.

\section{Antimicrobial activity}

The agar disc diffusion method was employed for the determination of antimicrobial activity of the papaya leaf extract stabilized gold nanoparticles. $0.1 \mathrm{ml}$ of $10^{8} \mathrm{cfu} /$ $\mathrm{ml}$ of different pathogenic bacterial suspension was spread on different plates nourished with LB media. Filter paper discs (5 $\mathrm{mm}$ in diameter) were placed on the plates and synthesized AuNPs and papaya leaf extract solutions were impregnated in different concentrations then onto the discs. Ampicillin $(10 \mu \mathrm{g} / \mathrm{ml}$ concentration), an antibiotic served as the standard for measuring the antibacterial activity. The plates were then incubated at $37{ }^{\circ} \mathrm{C}$ for $24 \mathrm{~h}$ and the zones of inhibition were measured (Majumdar et al. 2013).

\section{Results and discussion}

\section{UV-visible spectroscopy}

UV-visible spectroscopy is one of the most widely used techniques for determining the formation, stability and size of AuNPs in aqueous colloidal solution (Saha et al. 2010). The formation of AuNPs was indicated with a change of colour from yellow to blushing red. The colour change is attributed to the surface plasmon resonance (SPR). A characteristic SPR band for AuNPs is obtained around 520-530 nm (Praveen et al. 2011). Figure 1 shows the role of papaya leaf extract concentration on the formation of AuNPs, studied by microwaving the different concentrations $(0.1$ to $1 \%)$ of papaya leaf extract containing

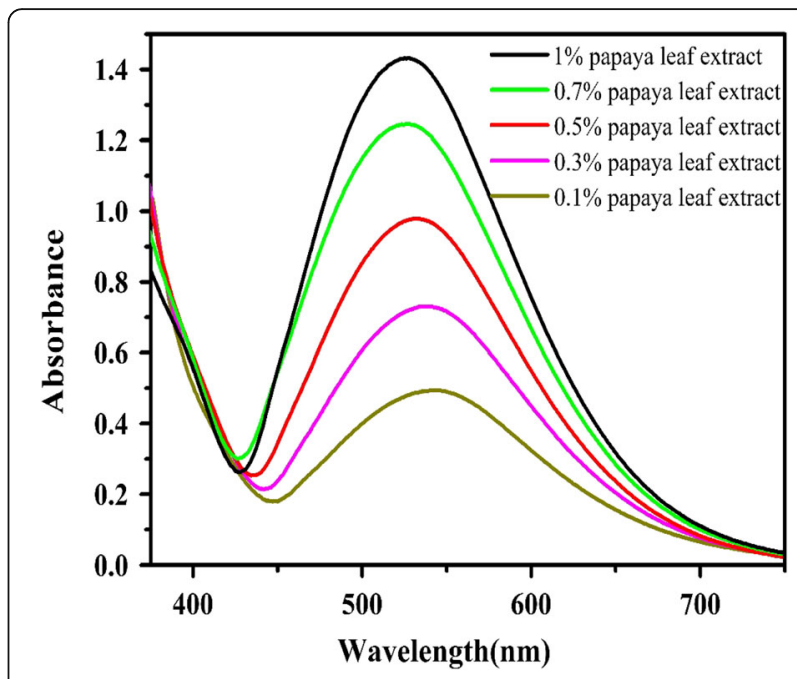

Fig. 1 The UV-vis absorption spectra of AuNPs synthesized by different concentration of papaya leaf extract solution at $1 \mathrm{mM}$ $\mathrm{HAuCl}_{4}$ concentration

$1 \mathrm{mM}$ of $\mathrm{HAuCl}_{4}$ for 2 min of time. With an increase in the concentration of papaya leaf extract, there is an enhancement in the concentration of AuNPs (Reddy et al. 2015b). Figure 2 shows the synthesis of nanoparticles by changing the concentration of $\mathrm{HAuCl}_{4}$ and the reduction was studied with $1 \%$ papaya leaf extract. It reveals that the efficiency of nanoparticle synthesis increases with increasing the concentration of $\mathrm{HAuCl}_{4}$.

\section{FTIR}

FTIR measurements were carried out to determine the possible functional groups in papaya leaf extract involved in the reduction and capping of synthesized gold

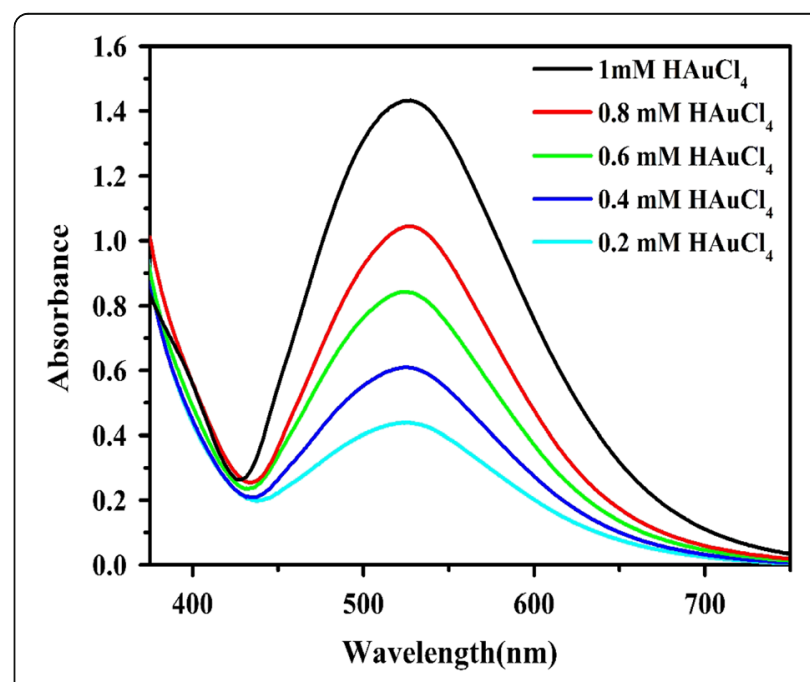

Fig. 2 The UV-vis absorption spectra of AuNPs synthesized by using different concentrations of $\mathrm{HAuCl}_{4}$ and $1 \%$ papaya leaf extract solution 
nano particles. Figure 3 shows the FTIR spectra of the papaya leaf extract and papaya leaf extract capped AuNPs. The major absorbance bonds present in the spectrum of papaya leaf extract were at 3245, 2862, $1810,1679,1491,1354,1106$, and $790 \mathrm{~cm}^{-1}$. The broad band observed at $3245 \mathrm{~cm}^{-1}$ could be assigned to stretching vibrations of $-\mathrm{OH}$ and $-\mathrm{NH}_{2}$ groups in the papaya leaf extract. The peak at $2862 \mathrm{~cm}^{-1}$ is due to asymmetric stretching vibrations of methylene groups. The peak at $1679 \mathrm{~cm}^{-1}$ is due to the $\mathrm{C}=\mathrm{O}$ stretching vibration of the carbonyl and carboxylic groups present in the amide linkage of the proteins. The symmetrical stretch of carboxylate group can be attributed to the bands present at 1491 and $1354 \mathrm{~cm}^{-1}$. The bands at 1105 and $789 \mathrm{~cm}^{-1}$ were due to the $\mathrm{C}-\mathrm{O}$ stretching vibrations of polyols, ether and alcoholic groups, and bending vibration of $\mathrm{C}-\mathrm{N}$.

Figure 3 curve $b$ shows the papaya leaf extract capped AuNPs characteristic absorbance bands at 3416, 2915, $1778,1716,1560,1410,1112$, and $787 \mathrm{~cm}^{-1}$. After formation of AuNPs, shifts in absorption peaks were observed from 3245 to $3416 \mathrm{~cm}^{-1}, 1810$ to $1778 \mathrm{~cm}^{-1}$, 1679 to $1716 \mathrm{~cm}^{-1}, 1491$ to $1560 \mathrm{~cm}^{-1}$ and 1354 to $1410 \mathrm{~cm}^{-1}$. After the encapsulation of gold nanoparticles, the peaks become weaker and are shifted, suggesting that the carbonyl groups of proteins and hydroxyl groups of alcohol and phenolics may be involving in the synthesis and stabilizing of AuNPs (Balakumar and Prakash 2015).

As discussed above, the components of papaya leaf extract contain a large number of hydroxyl and carboxylic groups which facilitate the complexation of Au3+ ions. Subsequently, these gold ions oxidize the hydroxyl groups to carbonyl groups, during which the gold ions are reduced to elemental gold. Further, these nanoparticles are

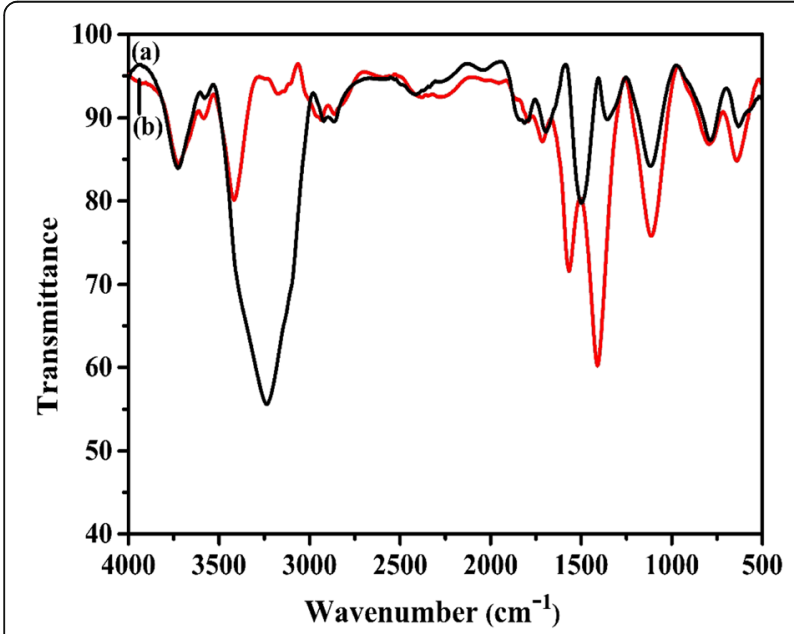

Fig. 3 FTIR spectra of (a) papaya leaf extract and (b) papaya leaf extract capped AuNPs probably capped and stabilized by the polyphenolic compounds and proteins present in the leaf extract.

\section{XRD}

The XRD analysis was used to determine the crystalline structure of synthesized AuNPs. For XRD analysis, the prepared sample was lyophilized and precipitated under vacuum then used for XRD analysis. In Fig. 4, intense diffraction peaks were observed at $2 \theta$ values of $38.24^{\circ}$, $44.30^{\circ}, 64.67^{\circ}$, and $77.66^{\circ}$, which were indexed to the (111), (200), (220), (311) reflections of crystalline metallic gold respectively. These values are similar to that given by Joint Committee on Powder Diffraction Standards (JCPDS no. 04-0784) revealing that synthesized AuNPs are of pure crystalline gold (Reddy et al. 2015b). The XRD pattern thus clearly shows that the AuNPs were crystalline in nature.

\section{Zeta potential}

Zeta potential values reveal details about the stability and surface charge of the synthesized AuNPs. Particles with highly negative or positive surface charge are considered to be stable. An absolute zeta potential value of $\pm 30 \mathrm{mV}$ is a general indication that the colloidal solution highly stable. Zeta potential (Fig. 5) of papaya leaf extract capped AuNPs is found to be $-22.5 \mathrm{mV}$, which clear indicates that the nanoparticles are negatively charged and highly stable.

\section{TEM}

TEM analysis was done to examine the particle shape and particle size of the green synthesized AuNPs using papaya leaf extract. Figure $6 a$ shows that the size of AuNPs ranges from 7 to $26 \mathrm{~nm}$. TEM analysis suggests that the synthesized papaya leaf extract capped AuNPs were spherical in shape and the average size of the AuNPs was $15 \pm 2$. The selected area

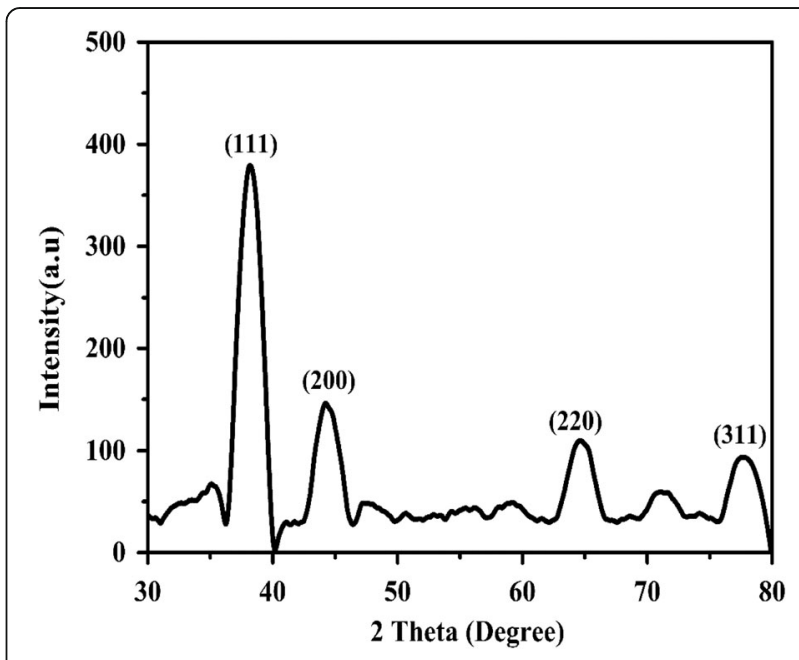

Fig. 4 XRD pattern of papaya leaf extract capped gold nanoparticles 


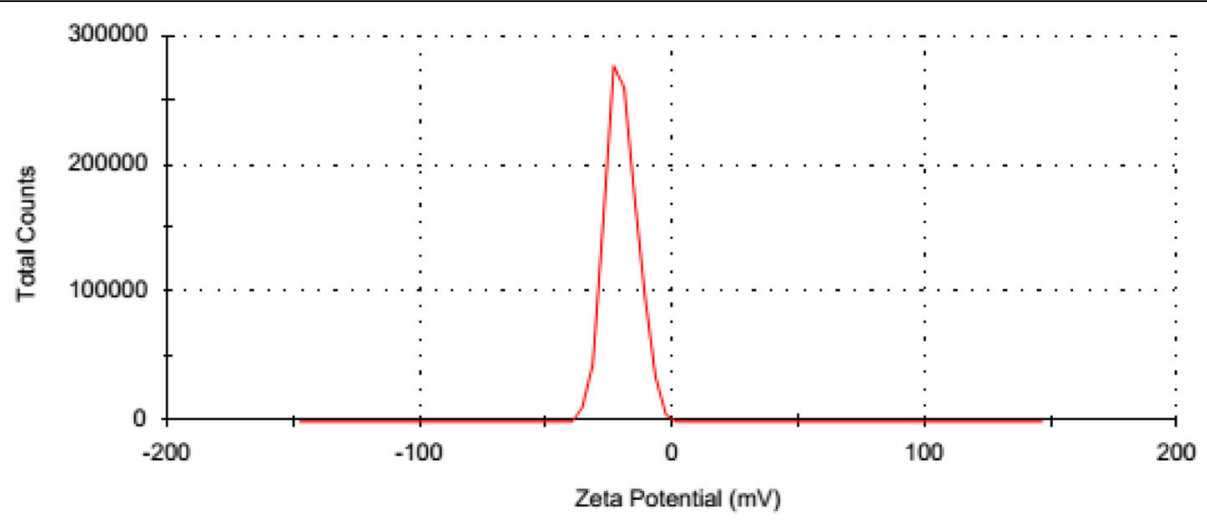

Fig. 5 Zeta potential plot of synthesized AuNPs

electron diffraction (Fig. 6b) pattern exhibited concentric rings with intermittent bright dots, indicating that these nano particles are highly crystalline nature. Histogram (Fig. 7) obtained by considering 120 nano particles suggests that there is a wide distribution of sizes from $11-18 \mathrm{~nm}$.

\section{Catalytic activity}

The catalytic activity of AuNPs stabilized in papaya leaf extract was evaluated for the reduction of toxic pollutant 4-NP in the presence of excess $\mathrm{NaBH}_{4}$. The catalytic reduction of 4-NP was studied in aqueous solution in a standard quartz cell with a $1-\mathrm{cm}$ path length. The products and substrates of this reaction were easily monitored by UV-Vis spectroscopy. In a typical run, $1 \mathrm{ml}$ of $0.02 \mathrm{M} \mathrm{NaBH}_{4}$ was mixed with $1.7 \mathrm{ml}$ of $0.15 \mathrm{mM} 4-\mathrm{NP}$ in a quartz cell. 4-NP solution is in light yellow color and exhibited a strong absorption peak at $317 \mathrm{~nm}$. Upon the addition of $\mathrm{NaBH}_{4}$ to the 4-NP the color changed to deep yellow color and a strong absorption peak at
$400 \mathrm{~nm}$ (Reddy et al. 2015c), due to the formation of pnitrophenolate ion (Fig. 8) was observed.

Through the reduction of 4-NP to 4-AP using $\mathrm{NaBH}_{4}$ is thermodynamically favorable $\left(\mathrm{E}^{\mathrm{o}}\right.$ for $\mathrm{H}_{3} \mathrm{BO}_{3} / \mathrm{BH}_{4}^{-}=-1.33 \mathrm{~V}$ and 4-NP/4-AP $=-0.76 \mathrm{~V}$ versus NHE). The presence of the kinetic barrier due to the large potential difference between donor and acceptor molecule decrease the feasibility of this reaction (Saha et al. 2010). The reaction was carried out at room temperature $\left(30{ }^{\circ} \mathrm{C}\right)$ for $1-3 \mathrm{~h}$ without the addition of AuNPs. It was observed that there was no change in the peak position at $400 \mathrm{~nm}$, which shows that no reaction could occur without the catalyst. This indicates that $\mathrm{NaBH}_{4}$ itself was not able to reduce of 4-NP.

There is a fall in the intensity of the peak at $400 \mathrm{~nm}$ of the p-Nitrophenolate ion on the addition of AuNPs, although, there is a concomitant appearance of a new peak at $297 \mathrm{~nm}$ indicating the formation of product 4AP (Fig. 8). The reduction reaction was complete within $16 \mathrm{~min}$. The reaction follows pseudo-first order kinetics with respect to 4-NP (Balakumar and Prakash 2015).

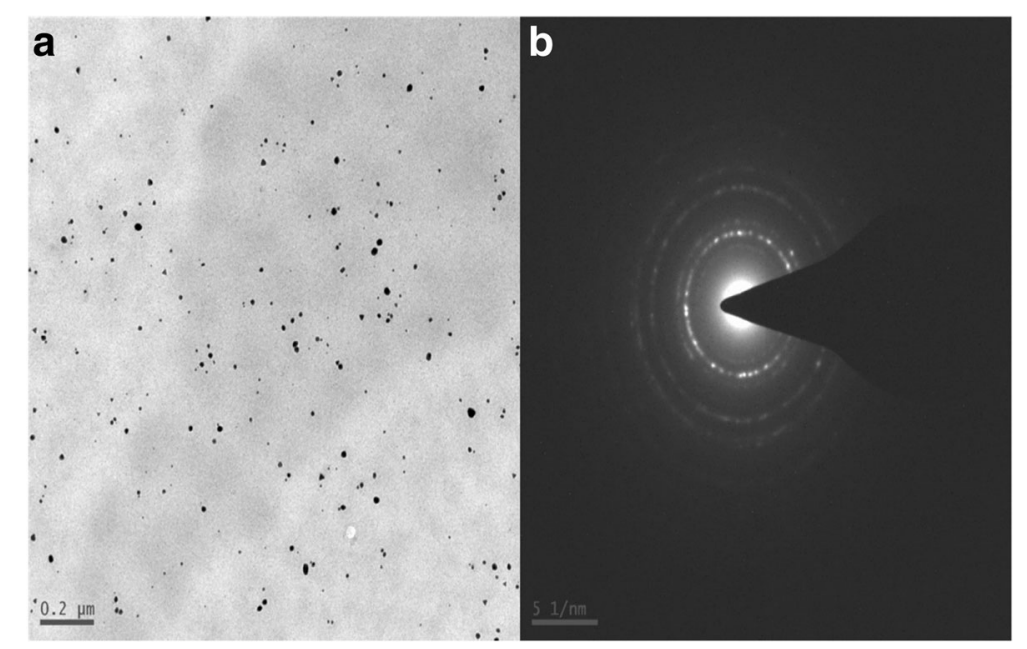

Fig. 6 (a) TEM image (b) corresponding SAED pattern of papaya leaf extract capped gold nanoparticles 


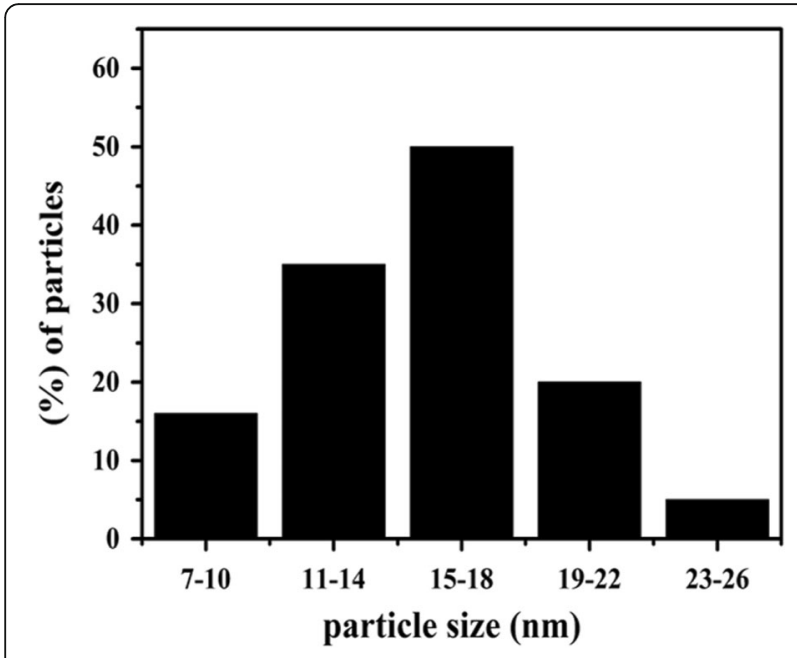

Fig. 7 Histogram showing the particle size distribution of papaya leaf extract capped gold nanoparticles

The concentration $\mathrm{NaBH}_{4}$ was much higher compared to 4-NP. The rate constant of the reaction was independent of $\mathrm{NaBH}_{4}$ concentration. The rate constant $(k)$ was (Fig. 9) determined from the linear plot of $\ln \left(\mathrm{A}_{t}\right)$ $\mathrm{A}_{0}$ ) versus reduction time.

The effect of $\mathrm{NaBH}_{4}$ concentration on the reduction of 4-NP was studied to select the optimum concentration of $\mathrm{NaBH}_{4}$ required. As depicted in Fig. 10, in the case of 4NP reduction using AuNPs catalyst, it was found that in the concentration range of $0.01-0.025 \mathrm{M}$ of borohydride, the rate increased with the increase in concentration, whereas in the range of $0.15-0.25 \mathrm{M}$, it remained constant. Thus, the borohydride concentration selected for the entire range was $0.015 \mathrm{M}$, which was a large excess

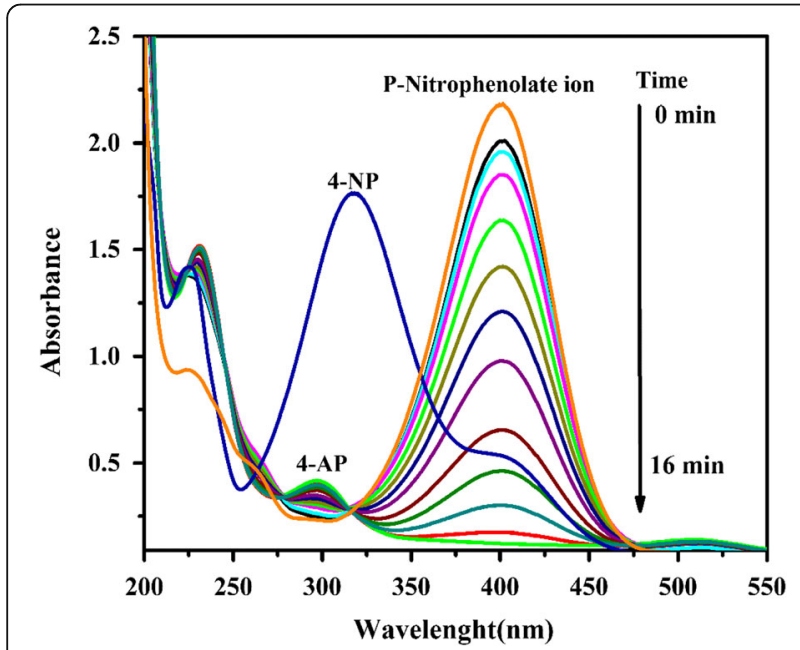

Fig. 8 Successive UV-vis absorption spectra of the reduction of 4-NP by $\mathrm{NaBH}_{4}$ in the presence of papaya leaf extract capped gold nanoparticle as catalyst

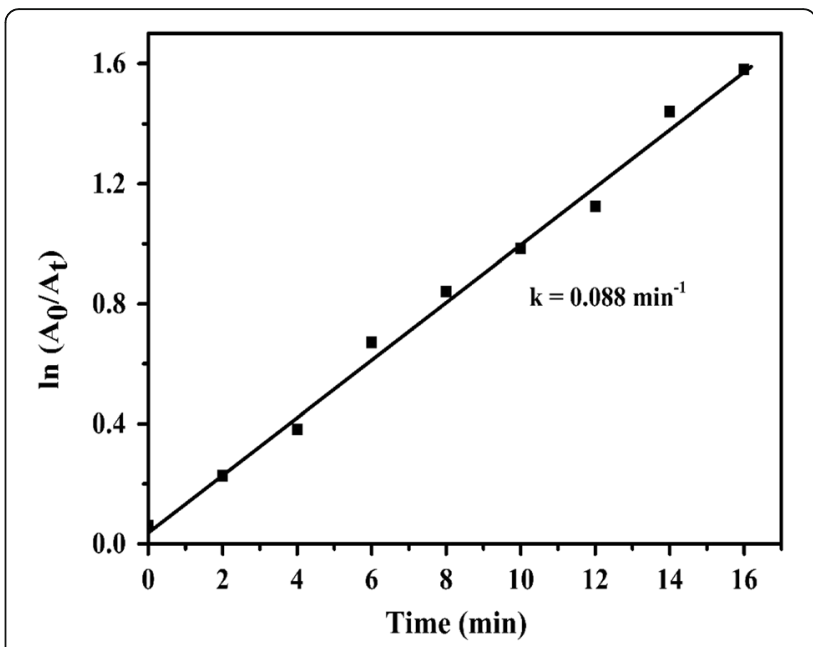

Fig. 9 Plot of $\ln \left(A_{t} / A_{0}\right)$ against the reaction time

compared to that of 4-NP, to make the reaction independent (zero-order) of borohydride concentration.

The effect of the amount of AuNPs on the reduction of 4-NP was studied using AuNPs from 50-300 $\mu \mathrm{L}$ keeping the other parameters such as temperature, concentration of $\mathrm{NaBH}_{4}$ and concentration of 4-NP constant. The rate constant for 50,100, 150, 200, 250 and, $300 \mu \mathrm{L}$ catalysts are $0.073,0.124,0.194,0.224$, and $0.310 \mathrm{~min}^{-1}$, respectively. The rate constant values are plotted against varying amounts of catalyst and are shown in Fig. 11. As anticipated, the rate constant has increased with an increase in the amount of AuNPs which is evident from Fig. 11, due to an increase in the number of reaction sites.

The effect of temperature was studied for the reduction of 4-NP to 4-AP. The activation energy $\left(E_{\mathrm{a}}\right)$ of the reaction was determined from the Arrhenius equation $k=\mathrm{Ae}^{-\mathrm{Ea} / \mathrm{RT}}$, where $\mathrm{A}$ is a constant and $\mathrm{R}$ is the

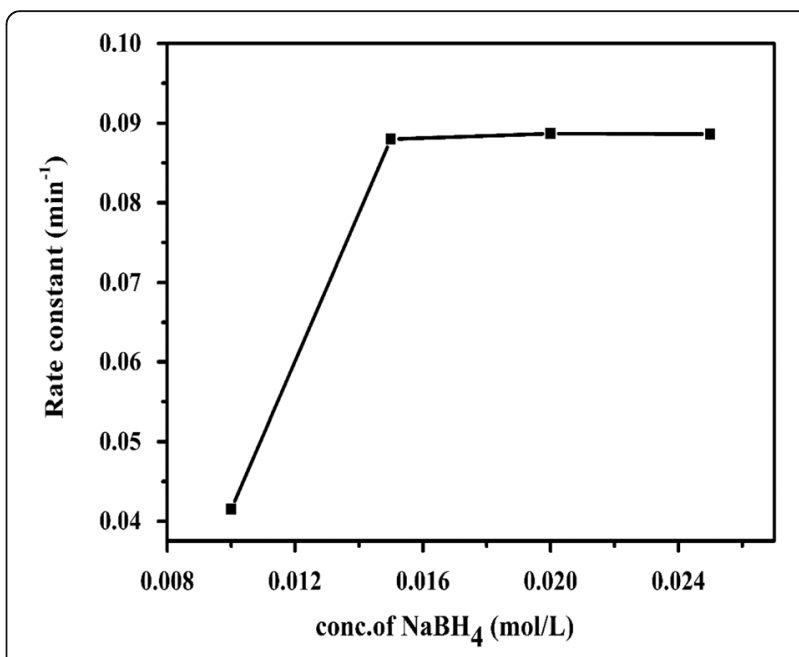

Fig. 10 Plot of rate constant versus concentration of $\mathrm{NaBH}_{4}$ 


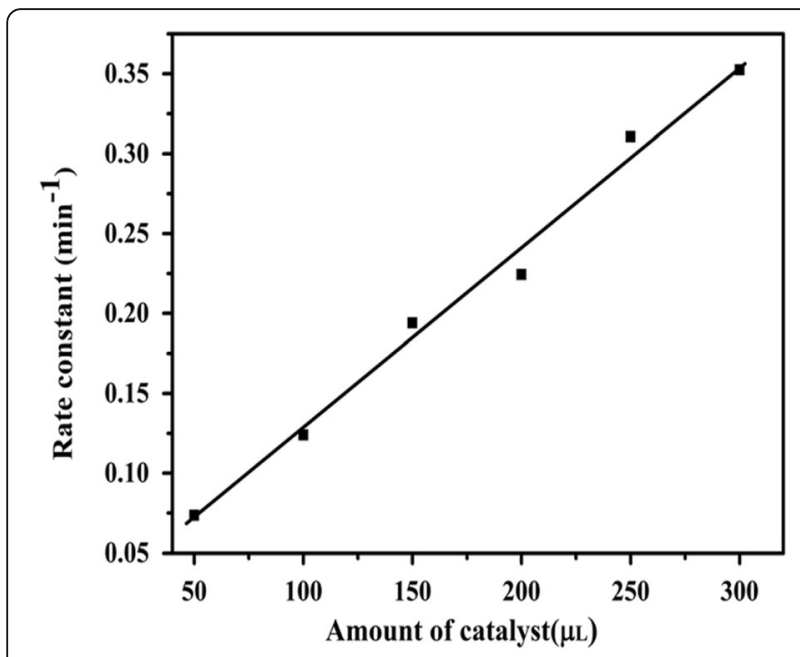

Fig. 11 Plot of rate constant ( $k$ ) versus amount of AuNPs

universal gas constant, $\mathrm{k}$ is rate constant of the reaction at temperature $\mathrm{T}$ (in kelvin). The reduction of 4-NP was studied at five different temperatures $(30,35,45,55$, and $65{ }^{\circ} \mathrm{C}$ ) using AuNPs as the catalyst. The rate constant of the reaction was calculated at five different temperatures. A plot of $\ln \mathrm{k}$ versus $1 / \mathrm{T}$, shown in Fig. 12, is linear for 4-NP reduction using AuNPs. It was noticed that the increase in temperature helps the rate of the reaction to increase. The catalytic studies were performed using the AuNPs, which exhibit higher catalytic performance compared to other earlier reported results (Reddy et al. 2015a; Tao et al. 2017). The activation energy was calculated from the slope $(-\mathrm{Ea} / \mathrm{R})$ of the straight line and was found to be $28.15 \pm 1.14 \mathrm{~kJ} / \mathrm{mol}$.

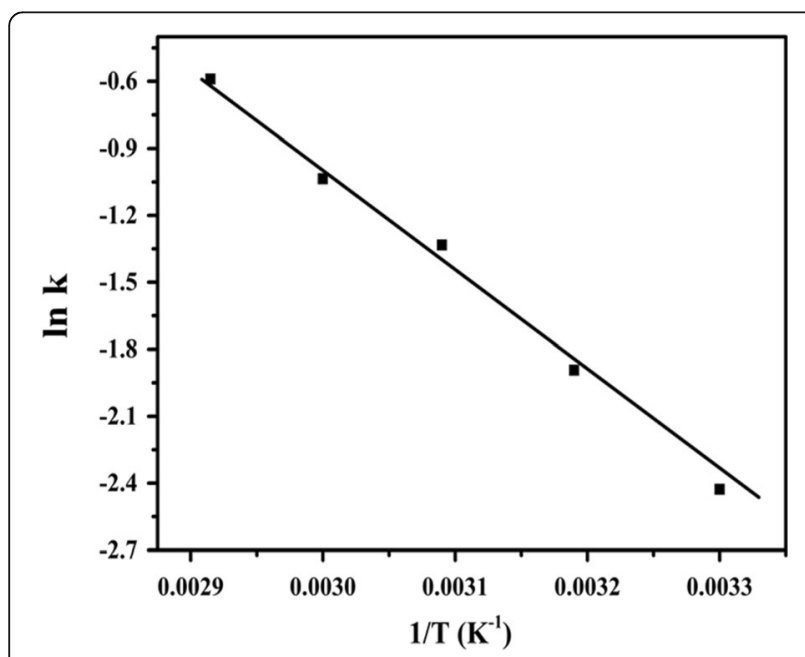

Fig. 12 Plot of rate constant against $1 / T$ for the reduction of $4-N P$ by $\mathrm{NaBH}_{4}$ in the presence of AuNPs as catalyst at different temperatures
Stability and reusability of the catalyst

Stability and reusability are important characteristics of a good catalyst. To investigate the reusability of papaya leaf extract capped AuNPs catalyst, recycling experiments were performed with the same catalyst. In this experiment, after completion of every reduction cycle, the catalyst was collected by centrifugation, dried and used for the next cycle of reduction. As shown in Fig. 13, the catalyst exhibited high activity even after four cycles of reaction. These results imply that the components of papaya leaf extract are effective in stabilizing the AuNPs during the catalytic reactions by preventing them from aggregation (Balakumar and Prakash 2015). Therefore, the papaya leaf extract capped AuNPs can serve as an effective catalyst.

\section{Anti-bacterial activity}

The papaya leaf extract capped AuNPs has significant antibacterial activity against Gram-negative Pseudomonas putida and Gram-positive Staphylococcus aureus. It revealed that as the concentration of AuNPs was increased, bacterial growth decreased in both the cases. The antimicrobial efficiency of AuNPs increases because of their larger total surface area per unit volume (Lokina and Narayanan 2013). The zone of inhibition of AuNPs against $P$. putida and $S$. aureus bacteria is shown in Fig. $14 \mathrm{a}, \mathrm{b}$. The results suggested that AuNPs synthesized from papaya leaf extract showed effective antibacterial activity in gram positive than in Gram-negative bacteria. A small zone of inhibition was observed for the papaya leaf extract alone. Antibacterial activities of AuNPs have been reported but their exact mechanisms of action are poorly understood. Rai et al. (2010) suggested AuNPs make holes in the cell wall, resulting in the fact that leakage of cell contents leads to death, and in another way it can bind to the DNA of bacteria and

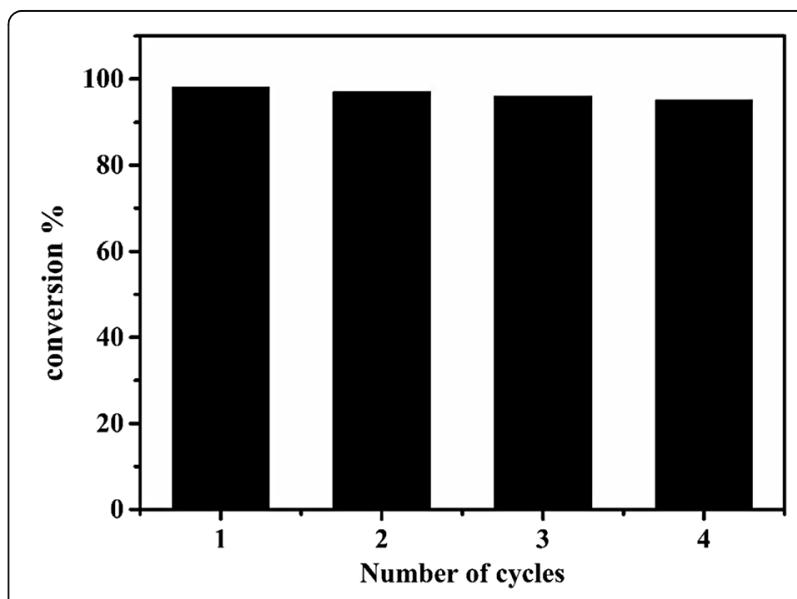

Fig. 13 Plot of percentage of conversion (4-NP to 4-AP) vs Number of cycles 


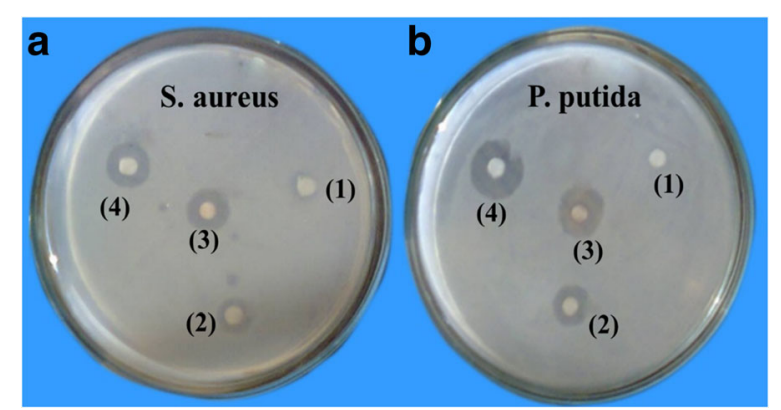

Fig. 14 Antibacterial activity of papaya leaf extract capped AuNPs using (a) Staphylococcus aureus (b) Pseudomonas putida $(1 \mathrm{mg} / \mathrm{ml}$ solution: discs containing $1=10 \mu$ of papaya leaf extract solution, $2=10 \mu \mathrm{l}$ of AuNPs, $3=20 \mu \mathrm{l}$ of AuNPs, $4=10 \mu \mathrm{l}$ of ampicillin)

inhibit the DNA transcription. Because AuNPs closely bind to the surface of the microorganism causing visible damage to the cells, it can minimize the treatment duration and side effects of drugs (Zawrah et al. 2011). It has been also reported that gold nanoparticles can penetrate and can disrupt the membranes of bacteria. These AuNPs decreased the ATP levels. Moreover, the phospholipid portion of the bacterial membrane may also be the site of action for the AuNPs (Eom et al. 2012). Based on these results, it can be concluded that the green synthesized AuNPs had significant antibacterial action on both bacteria.

\section{Conclusions}

The papaya leaf extract is an effective source for the green synthesis of AuNPs. The papaya leaf extract acts both as a reducing and as a capping agent. The green synthesized AuNPs were characterized by UV-vis, FTIR, $\mathrm{XRD}$, and TEM techniques. The XRD pattern revealed that the papaya leaf extract capped AuNPs were crystalline. FTIR suggest that both carbonyl groups of papaya leaf extract are involved in the synthesis and capping of AuNPs. TEM showed that the size and morphology of synthesized AuNPs were spherical in shape, with the average size distribution of $15 \pm 2 \mathrm{~nm}$. The catalytic activity of papaya leaf extract capped AuNPs was examined by the reduction of 4-NP. The detailed kinetic aspects for catalytic reduction of 4-NP were evaluated by changing parameters. It was observed that the concentration of $\mathrm{NaBH}_{4}$ does not affect much the reduction process. It was noticed that with an increasing in the amount of AuNPs and temperature, the total reaction time decreases and the rate of the reaction increases. The papaya leaf extract capped AuNPs showed effective antibacterial activity on both $P$. putida and S.aureus.

\section{Abbreviations}

4-AP: p-aminophenol; 4-NP: p-nitrophenol; AuNPs: Gold nanoparticles; cm: Centimeter; FTIR: Fourier transform infrared; g: Gram; GT: Gum tragacanth; min: Minute; $\mathrm{mL}$ : Milliliter; $\mathrm{nm}$ : Nanometer; rpm: Revolutions per minute; TEM: Transmission electron microscopy; w/v: Weight/volume; XRD: $x$-ray diffraction

\section{Acknowledgements}

The authors are thankful to Centre for nanotechnology, University of Hyderabad, for providing the TEM facility and Department of Chemistry, Osmania University, for providing infrastructure.

\section{Authors' contributions}

SS, BRG, and RKD synthesized the AUNPs. RKB collected papaya leaf and prepared the aqueous leaf extract. DRK characterized the AuNPs using UV-Vis spectroscopy. GBR characterized the AuNPs using X-ray diffraction and TEM. MA conducted the catalytic studies on AuNPs. GVB and SS contributed in analyzing the data. All authors read and approved the final manuscript.

\section{Competing interests}

The authors declare that they have no competing interests.

\section{Publisher's Note}

Springer Nature remains neutral with regard to jurisdictional claims in published maps and institutional affiliations.

\section{Author details}

'Department of Chemistry, University College of Science, Osmania University, Hyderabad, Telangana state 500007, India. ${ }^{2}$ Department of Chemistry, PG center Wanaparthy, Palamuru University, Mahbubnagar, Telangana state 509001, India. ${ }^{3}$ Department of Chemistry, College of Natural and Computational Sciences, Gondar University, P.O. Box,196, Gondar, Ethiopia.

Received: 7 January 2017 Accepted: 26 April 2017

Published online: 03 June 2017

\section{References}

Adelere IA, Lateef A. A novel approach to the green synthesis of metallic nanoparticles: the use of agro-wastes, enzymes and pigments. Nanotechnol Rev. 2016;5:567-87.

Aravind G, Debjit B, Duraivel S, Harish G. Traditional and medicinal uses of carica papaya. J Med Plants Stud. 2013;1:7-15.

Balakumar V, Prakash P. Silver-nanospheres as a green catalyst for the decontamination of hazardous pollutants. RSC Adv. 2015;5:105917-24.

Balakumar V, Prakash P. Silver Nanoparticles Embedded RGO-Nanosponge for Superior Catalytic Activity towards 4-nitrophenol Reduction. RSC Adv. $2016 a$. do: 10.1039/C6RA19834A.

Balakumar V, Prakash P. A facile, one-pot and eco-friendly synthesis of gold/silver nanobimetallics smartened $\mathrm{rGO}$ for enhanced catalytic reduction of hexavalent chromium. RSC Adv. 2016b;6:57380-8.

Barad J, Chakraborty M. Reduction of 4-nitrophenol and 4-nitrobenzo 15 crown with colloidal platinum nanoparticles synthesized by microemulsion technique. Part Sci Technol. 2014;32:164-70.

Chao L, Kai T, Dayin H, Zhen M, Shenghu Z. Size Effect of Gold Nanoparticles in Catalytic Reduction of p-Nitrophenol with NaBH4. Molecules. 2013;18:12609-20.

Cuenca AG, Jiang H, Hochwald SN, Delano M, Cance WG, Grobmyer SR. Emerg- ing implications of nanotechnology on cancer diagnostics and therapeutics. Cancer. 2006;107:459-66.

Dahl JA, Maddux BLS, Hutchison JE. Toward Greener Nanosynthesis. Chem Rev. 2007;107:2228-69.

Deng H, Li G, Liu A, Chen W. Thermally Treated Bare Gold Nanoparticles for Colorimetric Sensing of Copper lons. Microchim Acta. 2014;181:911-6.

Eom SH, Kim YM, Kim SK. Antimicrobial effect of phlorotannins from marine brown algae. Food Chem Toxicol. 2012;50:3251-5.

Farkas J, Christian P, Urrea JA, Roos N, vd Hassello M, Tollefsen KE. Effects of silver and gold nanoparticles on rainbow trout (Oncorhynchus mykiss) hepatocytes. Aquat Toxicol. 2010;96:44-52.

Gan PP, Ng SH, Huang Y, Fong S, Li Y. Green Synthesis of Gold Nanoparticles Using Palm Oil Mill Effluent (POME): A Low-Cost and Eco-Friendly Viable Approach. Bioresour Technol. 2012;113:132-5.

Gangula A, Podila RMR, Karanam L, Janardhana C, Rao AM. Catalytic Reduction of 4-Nitrophenol Using Biogenic Gold and Silver Nanoparticles Derived from Breynia Rhamnoides. Langmuir. 2011;27:15268-74.

Ju KS, Parales RE. Nitroaromatic compounds, from synthesis to biodegradation. Microbiol Mol Biol Rev. 2010;74:250-72. 
Kadry MS. Antioxidant and immunostimulant effect of Carica papaya aqueous extract in acrylamide intoxicated rats. Acta Inform Med. 2012;20:180-5.

Lateef A, Ojo SA, Elegbede JA. The emerging roles of arthropods and their metabolites in the green synthesis of metallic nanoparticles. Nanotechnol Rev. 2016;5:601-22.

Layek K, Kantam ML, Shirai M, Nishio-hamane D, Sasaki T, Maheswaran H. Gold Nanoparticles Stabilized on Nanocrystalline Magnesium Oxide as an Active Catalyst for Reduction of Nitroarenes in Aqueous Medium at Room. Green Chem. 2012;14:3164-74

Lokina S, Narayanan V. Antimicrobial and anticancer activity of gold nanoparticles synthesized from grapes fruit extract. Chem Sci Trans. 2013;2:105-10.

Madhusudhan A, Reddy GB, Venkatesham M, Veerabhadram G. Efficient pH Dependent Drug Delivery to Target Cancer Cells by Gold Nanoparticles Capped with Carboxymethyl Chitosan. Int J Mol Sci. 2014;15:8216-34.

Majumdar R, Bag BG, Maity N. Acacia Nilotica (Babool) Leaf Extract Mediated Size-Controlled Rapid Synthesis of Gold Nanoparticles and Study of Its Catalytic Activity. Int Nano Lett. 2013;3:1-6.

Martı'nez JA, Chequer NL, Gonza'lez J, Cordova T. Alternative for gold nanoparticles diameter characterization using PCA technique and UV-VIS spectrophotometry. Nanosci Nanotechnol. 2012;2:184-9.

Murray RW. Nanoelectrochemistry: metal nanoparticles, nanoelectrodes, and nanopores. Chem Rev. 2008;108:2688-720.

Ojo SA, Lateef A, Azeez MA, Oladejo SM, Akinwale AS, Asafa TB, Yekeen TA, Akinboro A, Oladipo IC, Gueguim-Kana EB, Beukes LS. Biomedical and catalytic applications of gold and silver-gold alloy nanoparticles biosynthesized using cell-free extract of Bacillus safensis LAU 13: antifungal, dye degradation, anti-coagulant and thrombolytic activities. EEE Trans Nanobioscience. 2016;15:433-42.

Prakash P, Gnanaprakasama P, Emmanuel R, Arokiyaraj S, Saravanan M. Green synthesis of silver nanoparticles from leaf extract of Mimusopselengi, Linn. for enhanced antibacterial activity against multi drug resistant clinical isolates. Colloids Surf B: Biointerfaces. 2013;108:255-9.

Praveen K, Willi P, Chandra P. Sharma: Green synthesis of gold nanoparticles with Zingiber officinale extract: Characterization and blood compatibility. Process Biochem. 2011;46:2007-13.

Punuri J, Sharma P, Sibyala S, Tamuli R, Bora U. Piper Betle-Mediated Green Synthesis of Biocompatible Gold Nanoparticles. Int Nano Lett. 2012;2:18-26.

Rai A, Prabhune A, Perry CC. Antibiotic mediated synthesis of gold nanoparticles with potent antimicrobial activity and their application in antimicrobial coatings. J Mater Chem. 2010;20:6789-98.

Rashed KN, Michele GC, Geovana PGV, Lizandra GM, Wilson RC. Evaluation of schistosomicidal and leishmanicidal activities from Carica papaya (Linn.) stem and phytochemical composition. Topclass J Herbal Med. 2013;2:239-24.

Reddy GB, Ramakrishna D, Madhusudhan A, Ayodhya D, Venkatesham M, Veerabhadram G. Catalytic Reduction of P-Nitrophenol and Hexacyanoferrate (III) by Borohydride Using Green Synthesized Gold Nanoparticles. J Chin Chem Soc. 2015a;62:420-8.

Reddy GB, Madhusudhan A, Ramakrishna D, Ayodhya D, Venkatesham M, Veerabhadram G. Green Chemistry Approach for the Synthesis of Gold Nanoparticles with Gum Kondagogu: Characterization, Catalytic and Antibacterial Activity. J Nanostruct Chem. 2015b;5:185-93.

Reddy R, Babu V, Karnati PR. Green Synthesis and Characterization of Carica Papaya Leaf Extract Coated Silver Nanoparticles through X-Ray Diffraction Electron Microscopy and Evaluation of Bactericidal Properties. Saudi J Biol Sci. 2015c;22:637-44

Rodrı'guez-Sa'nchez L, Blanco MC, Lo'pez-Quintela MA. Electrochemical Synthesis of Silver Nanoparticles. J Phys Chem. 2000;B104:9683-8.

Sadeghi B. Zizyphus Mauritiana Extract-Mediated Green and Rapid Synthesis of Gold Nanoparticles and Its Antibacterial Activity. J Nanostruct Chem. 2015. doi:10.1007/s40097-015-0157-y.

Saha S, Pal A, Kundu S, Basu S, Pal T. Photochemical Green Synthesis of CalciumAlginate-Stabilized Ag and Au Nanoparticles and Their Catalytic Application to 4-Nitrophenol Reduction. Langmuir. 2010;26:2885-93.

Sardar R, Funston AM, Mulvaney P, Murray RW. Gold nanoparticles: past, present, and future. Langmuir. 2009;25:13840-51.

Seigler DS, Pauli GF, Nahrstedt A, Leen R. Cyanogenic allosides and glucosides fromPassiflora edulisandCarica papaya. Phyto Chem. 2002;60:873-82.

Siavash I. Green Chemistry Green Synthesis of Metal Nanoparticles Using Plants. Green Chem. 2011;13:2638-50
Sinhalagoda LCAD, Susiji W, Roshitha NW, Rajapakse PVJR, Senanayake AMK. Caricapapayaleafextract increase the platelet count? An experimental study in amurine model. Asian Pac J Trop Biomed. 2013;3:720-4.

Tao M, Wenshuo $Y$, Simin L, Haijun Z, Feng L. A comparison reduction of 4-Nitrophenol by gold nanospheres and gold nanoparticles. Catalysts. 2017:7:38-48.

Ulvestad A, Clark JN, Harder R, Robinson IK, Shpyrko OG. 3D Imaging of Twin Domain Defects in Gold Nanoparticles. Nano Lett. 2015;15:4066-70.

White II GV, Kerscher P, Brown RM, Morella JD, Mcallister W, Dean D, Kitchens CL. Green Synthesis of Robust, Biocompatible Silver Nanoparticles Using Garlic Extract. J Nanomaterials. 2012. doi:10.1155/2012/730746.

Zawrah MF, Abd el-moez SI, Center D. Antimicrobial activities of gold nanoparticles against major foodborne pathogens. Life Sci. 2011:8:37-44.

\section{Submit your manuscript to a SpringerOpen ${ }^{\circ}$ journal and benefit from:}

- Convenient online submission

- Rigorous peer review

- Immediate publication on acceptance

- Open access: articles freely available online

- High visibility within the field

- Retaining the copyright to your article

Submit your next manuscript at $>$ springeropen.com 